\title{
cmaJOPEN
}

\section{Assessment of capacity to give informed consent for medical assistance in dying: a qualitative study of clinicians' experience}

\author{
Ellen Wiebe MD, Michaela Kelly MSc, Thomas McMorrow DCL, Sabrina Tremblay-Huet LLM, \\ Mirna Hennawy BSc
}

Abstract

Background: Under the Canadian Criminal Code, medical assistance in dying (MAiD) requires that patients give informed consent and that their ability to consent is assessed by 2 clinicians. In this study, we intended to understand how Canadian clinicians assessed capacity in people requesting MAiD.

Methods: This qualitative study used interviews conducted between August 2019 and February 2020, by phone, video and email, to explore how clinicians assessed capacity in people requesting MAiD, what challenges they had encountered and what tools they used. The participants were recruited from provider mailing listserves of the Canadian Association of MAiD Assessors and Providers and Aide médicale à mourir. Interviews were audio-recorded and transcribed verbatim. The research team met to review transcripts and explore themes as they emerged in an iterative manner. We used abductive reasoning for thematic analysis and coding, and continued to discuss until we reached consensus.

Results: The 20 participants worked in 5 of 10 provinces across Canada, represented different specialties and had experience assessing a total of 2410 patients requesting MAiD. The main theme was that, for most assessments, the participants used the conversation about how the patient had come to choose MAiD to get the information they needed. When the participants used formal capacity assessment tools, this was mostly for meticulous documentation, and they rarely asked for psychiatric consults. The participants described how they approached assessing cases of nonverbal patients and other challenging cases, using techniques such as ensuring a quiet environment and adequate hearing aids, and using questions requiring only "yes" or "no" as an answer.

Interpretation: The participants were comfortable doing MAiD assessments and used their clinical judgment and experience to assess capacity in ways similar to other clinical practices. The findings of this study suggest that experienced MAiD assessors do not routinely require formal capacity assessments or tools to assess capacity in patients requesting MAiD.

\begin{abstract}
n 2016, Canada's parliament passed An Act to amend the Criminal Code and to make related amendments to other Acts (medical assistance in dying), known as Bill C-14. The law permits physicians and nurse practitioners to give a lethal substance to any patient suffering from a "grievous and irremediable medical condition," who voluntarily requests medical assistance in dying (MAiD) and satisfies the eligibility criteria. ${ }^{1}$ The act requires that patients "give informed consent to receive medical assistance in dying after having been informed of the means that are available to relieve their suffering, including palliative care" and that clinicians "immediately before providing the medical assistance in dying ... ensure that the person gives express consent to receive medical assistance in dying." Quebec physicians are additionally subject to the provincial Act Respecting End-of-Life Care, which likewise requires patients to provide "free" and "informed" consent. ${ }^{2}$
\end{abstract}

Having legal capacity means being able to understand the information relevant to making a decision about treatment and being able to appreciate the reasonably foreseeable consequences of making that decision. ${ }^{3}$ All forms of medical intervention performed by clinicians require informed consent. ${ }^{4}$ Informed consent is task, context and time specific and requires voluntary choice in a patient who has been adequately informed and who has capacity to consent. ${ }^{4-7}$ The

\section{Competing interests: None declared.}

This article has been peer reviewed.

Correspondence to: Ellen Wiebe, ellenwiebe@gmail.com

CMAJ Open 2021. DOI:10.9778/cmajo.20200136 
assessment of capacity can be affected by contextual factors, including the experience and values of the assessor. ${ }^{8}$

Various tools have been validated for capacity assessments, such as the Aid to Capacity Assessment ${ }^{9}$ and the MacArthur Competence Assessment Tool - Treatment. ${ }^{10}$ None of these has been validated specifically for MAiD, but most accepted tools include the following elements:

1. Understanding information relevant to a condition and recommended treatment;

2. Appreciating the nature of their situation and the consequences of their choices;

3. Reasoning about the potential risks and benefits of their choices; and

4. Expressing a choice.

The presumption of intact decisional capacity is a bioethical standard. ${ }^{5,11}$ Patients with conditions such as dementia, mental illness and communication barriers pose specific challenges to assessors. In dementia, the domain of understanding has been shown to be most frequently deficient, as it relies most heavily on short-term memory. ${ }^{12-17}$ When mental illness impairs capacity, it most often affects the "appreciation" clause, which reflects insight. ${ }^{18}$ When assessing patients with communication barriers, it is not their communication skills but their decision-making capacity that must be assessed. To do so effectively, assessors must facilitate and maximize a patient's communication abilities. ${ }^{19}$

Our purpose was to understand how clinicians assessed capacity in people requesting MAiD, what challenges they had encountered and what tools they used, by exploring the experience of MAiD clinicians across Canada. This information is important for both training new assessors and informing policy.

\section{Methods}

\section{Study design}

This was a qualitative study using semistructured interviews. Given that the literature on assessing capacity in MAiD is in its infancy, we chose to use qualitative methodology to gain a broader understanding of the experiences of those who work in this area.

\section{Recruitment}

We recruited participants using the Canadian English and French MAiD provider listserves. The listserves include about 120 providers, and each member has been screened by the sponsoring organizations (Canadian Association of MAiD Assessors and Providers [CAMAP] and Aide médicale à mourir). The initial invitation was emailed to the French listserve on Aug. 14, 2019, and to the English listserve on Sept. 18, 2019, and follow-up invitations were sent 2 weeks after the first invitation. The invitations informed potential participants of the purpose of the study and the background of the investigators (Appendix 1, available at www.cmajopen.ca/content/9/2/E358/suppl/DC1). The only inclusion criteria were experience as a MAiD assessor and availability for interviews.

\section{Data collection and management}

The interview guide was developed with the help of the CAMAP working group on assessment for capacity to give informed consent for MAiD (https://camapcanada.ca/) (Appendix 2, available at www.cmajopen.ca/content/9/2/ E358/supp1/DC1). There were 8 members in the working group, including 1 member of the research team (E.W.). The working group was made up of experts including a psychiatrist, a geriatrician, a speech and language pathologist, and clinician MAiD providers who had created guidelines for MAiD assessors and providers. The working group defined the important issues for the interview guide. The interview guide was revised in an iterative manner as the research team reviewed the initial transcripts and decided that certain issues needed to be explored more fully in future interviews.

Two of the investigators conducted the interviews (M.K. in English and S.T.-H. in French) by phone, video or email, depending on the participant's preference. Both interviewers had experience conducting semistructured interviews for qualitative research. We asked participants about their experience in assessing capacity for MAiD, any challenges or problems they faced and the resources they used. The interviews ranged from 20 to 45 minutes and were conducted between August 2019 and February 2020. The phone and video interviews were audio-recorded and transcribed verbatim. S.T.-H. translated the French transcripts into English.

\section{Data analysis}

Phone, video and email interviews were analyzed together in English. We reached theme saturation early, but continued to recruit until we had a range of geographic and professional representation. Each author reviewed the interview transcripts as they were completed, making notes and observations about emerging themes in the data. We met to discuss recurrent themes in the interview responses, with M.H. taking the lead on developing a coding scheme, which we used to analyze all the data. Themes were expanded or refined in light of the coding process. When we realized that only some participants described the challenges of assessing patients with diagnoses of mental illness, we contacted the 13 interviewees who had not mentioned this and asked more questions about this issue.

Throughout analysis, we used abductive reasoning to "zoom out" to look first at the whole picture and identify the areas that were the most important to the participants (i.e., major and minor themes). ${ }^{20,21}$ Then, we "zoomed in" to discuss coding and reach consensus on a codebook. When data collection was complete and we had reached theme saturation, M.H. and M.K. completed the coding and then we all met to discuss and review the coded transcripts. Finally, we "zoomed out" again, using the codes to define themes and subthemes until we arrived at a consensus.

Demographic data were analyzed using descriptive statistics. For quantitative variables, means, medians and interquartile ranges were calculated using STATA version 15. 


\section{Ethics approval}

This study was approved by the University of British Columbia Research Ethics Board (H15-03198) and the Ontario Tech University Research Ethics Board (15221).

\section{Results}

There were $20 \mathrm{MAiD}$ assessors or providers who responded to our invitation and all participated in an interview (Table 1). Based on the participants' preferences, 14 interviews were conducted by phone, 5 by video and 1 by email. The interviews ranged from 20 to 45 minutes. All 13 follow-up interviews were done by email. Eight participants were interviewed in French and 12 in English.

The ages of participants ranged from 36 to 82 (mean 56) years, and they lived in 5 provinces; 8 were from Quebec and 12 were from the rest of Canada. Their clinical backgrounds included work in palliative care $(n=9)$, geriatrics $(n=4)$, emergency medicine $(n=2)$, intensive care $(n=2)$, reproductive health $(n=2)$, psychiatry $(n=3)$ and general medicine $(n=4)$. They spoke of diverse experiences working in hospitals, clinics, communities and homes. The participants had assessed between 8 and 500 patients for MAiD. Collectively, they had completed 2410 assessments at the time of their interviews during a period in which there were about 10000 MAiD deaths in Canada (Table 1).

We identified 3 major themes and 2 minor themes. The major themes were using conversation to assess capacity, strategies to cope with challenges and patients losing capacity because of terminal delirium. The minor themes were using intuition to assess capacity and dealing with concurrent mental illness.

\section{Major themes}

\section{Using conversation to assess capacity}

The most important theme was that participants usually gathered the information they needed through a conversation with the patient about how that individual had come to choose MAiD. The clinicians were comfortable assessing capacity and rarely referred for formal assessments. The Quebec providers, whose assessments are subject to review from Quebec's Commission on End-of-life Care, were more likely to say they used a tool, specifically the Nova Scotia criteria, to assess capacity (Box 1). ${ }^{22}$

\section{Strategies to cope with challenges}

When we asked about the challenges that they faced, participants described patients who were nonverbal or were so ill that they tired too quickly to have lengthy conversations, patients with fluctuating capacity and patients with early dementia. They talked about the ways they tried to foster conditions in which the patient could demonstrate capacity. They also used assistance from colleagues and corroborating evidence from family and caregivers (Box 2).

\section{Patients losing capacity because of terminal delirium}

The most common situation in which participants assessed someone as not eligible because of lack of capacity
Table 1: Characteristics of study participants

\begin{tabular}{|lc|}
\hline Characteristic & $\begin{array}{c}\text { No. of participants }(\%)^{*} \\
n=20\end{array}$ \\
\hline Sex & $11(55)$ \\
\hline Female & $9(45)$ \\
\hline Male & $18(90)$ \\
\hline Profession & $2(10)$ \\
\hline Physician & $2(10)$ \\
\hline Nurse practitioner & $1(5)$ \\
\hline Province & $8(40)$ \\
\hline British Columbia & $8(40)$ \\
\hline Manitoba & $1(5)$ \\
\hline Ontario & \\
\hline Quebec & $4(20)$ \\
\hline Saskatchewan & $14(70)$ \\
\hline Community of practice & $2(10)$ \\
\hline Rural & $43(20-151)$ \\
\hline Urban & $57(44-65)$ \\
\hline Mixed & \\
\hline $\begin{array}{l}\text { No. of MAiD assessments, } \\
\text { median (IQR) }\end{array}$ & \\
\hline Age, yr, median (IQR) & \\
\hline $\begin{array}{l}\text { Note: IQR = interquartile range, MAiD = medical assistance in dying. } \\
\text { Unless specified otherwise. }\end{array}$ & \\
\hline & \\
\hline
\end{tabular}

Box 1: Major theme: examples of quotes reflecting participants' use of conversation to assess capacity

- So you know, it's more my clinical experience, to chat, to discuss with the patient, and how I cross-check that with the patient's file, and I say "Well look, evidently he's coherent, he tells his story exactly, and he explained to me the road that allows me to determine why this patient made a MAiD request, he is aware of his diagnosis, he is aware that his diagnosis is terminal, and he wants to put an end to his life or to his struggle, because for him, it doesn't make any sense." (Participant 7, MD, Quebec*)

- I think my capacity assessment really stems from having a conversation with the patient and asking them to talk to me about their life and about their experiences, and it's through the answering and the understanding of those questions on their part that helps me to determine whether they have capacity to make this decision or not. (Participant $9, \mathrm{NP}, \mathrm{ROC}$ )

- It's always the Nova Scotia criteria, specifically, it's if the patient understands his illness, understands his prognosis, understands the options, understands what MAiD means, the advantages and disadvantages, and is able to reason, to reflect on that. (Participant 4, MD, Quebec*)

- I will go through the rigmarole [of using an assessment tool], because I know somebody may ask for my file, or somebody might contest, or a family member might contest. (Participant 3, MD, Quebec*)

Note: $\mathrm{MAiD}=$ medical assistance in dying, $\mathrm{MD}=$ physician, $\mathrm{NP}=$ nurse practitioner, $\mathrm{ROC}=$ rest of Canada.

*All of the quotes from participants in Quebec were translated from French to English. 
Box 2: Major theme: examples of quotes reflecting participants' discussion of strategies to cope with challenges

- l've learned more about facilitating capacity which means that you choose the right time of day and you make sure that the light is okay and it's quiet and that they've got their hearing aids and their glasses on. (Participant 10, MD, ROC)

- ... using simple language, being very repetitive. Simple language, slow language, so one item at a time, as opposed to a multi-layered sentence, or multi-layered question ... . Lots of repetition, lots of recall tests and checking in. (Participant 17, $\mathrm{MD}, \mathrm{ROC}$ )

- And so, you might ... go back and do repeat assessments, especially if they don't want the death right away, to make sure that they still have capacity. (Participant 18, MD, ROC)

- I really learnt a lot from the speech language pathologists. We've actually put together kind of a toolkit with a lot of pictures and schematics and stuff for patients with aphasia. (Participant 17, MD, ROC)

- I love having more ears involved, so I involve families as much as possible and that helps a lot too in helping Mom or Dad stay focused and determining whether they can get back on track and understand this. And I even use - if my language isn't right, then can their children come up with a different question? Can they reframe it to help Mom or Dad understand it better? (Participant 11, MD, ROC)

- In this particular patient's case, MAiD was something he had always been enthusiastic about. So, if the request is consistent with their values, even if their assessment is somewhat borderline, I often do feel comfortable saying that it's safe to proceed. That's one of my litmus tests. (Participant 16, MD, $\mathrm{ROC})$

Note: $\mathrm{MAiD}=$ medical assistance in dying, $\mathrm{MD}=$ physician, $\mathrm{ROC}=$ rest of Canada.

was in terminal delirium. They talked about expediting provision in patients they assessed as at risk of losing capacity (Box 3).

\section{Minor themes}

There were 2 minor themes identified: using intuition to assess capacity and dealing with concurrent mental illness. Some participants referred to their intuition or gut feeling making them want to take further steps to verify the patient's capacity (Box 4). Except for the psychiatrists, most participants had no experience with patients with "purely psychiatric" diagnoses. With patients who had concurrent conditions, they usually used the same approach as with their other patients (Box 5; this information was obtained from both the first and second interviews).

\section{Disagreements among colleagues}

We specifically asked our participants about whether they had had disagreements with colleagues about capacity, but most had not and no one had serious problems with this.

\section{Training}

Most of our participants relied on previous experiences and support from colleagues more than formal training in assessing capacity.
Box 3: Major theme: examples of quotes reflecting participants' experience working with patients with terminal delirium

- I think the patients that I had to deem ineligible because of capacity were clearly far along in their illness trajectory and were very close to their natural death. (Participant 9, NP, $\mathrm{ROC})$

- And so he went through a very rapid decline and so we expedited, but that day, by one o'clock in the afternoon, by the time I got the second assessment done, he actually couldn't say yes or no anymore. (Participant $13, \mathrm{MD}, \mathrm{ROC}$ )

- It's that a lot of patients refuse to receive palliative care medication by fear of losing their capacity to consent in the process. (Participant 6, MD, Quebec*)

- I won't say “it's now or never," but l'll kind of just say, "We're not going be able to wait the 10 days, so we're going to try to get the 2 assessments in today and tomorrow and pick a date as soon as we know that both physicians feel you qualify." (Participant 19, MD, ROC)

Note: $\mathrm{MD}=$ physician, $\mathrm{NP}=$ nurse practitioner, $\mathrm{ROC}=$ rest of Canada. *All of the quotes from participants in Quebec were translated from French to English.

Box 4: Minor theme: example of quote reflecting participants' discussion of intuition

- You know, sometimes it really is 2 patients who are very similar, but with one of them you feel confident, and the other you don't, and it's hard to put your finger on why that is. (Participant 16, MD, ROC)

Note: $\mathrm{MD}=$ physician, $\mathrm{ROC}=$ rest of Canada.

\section{Box 5: Minor theme: example of quotes reflecting} participants' views of concurrent mental illness

- As mental health issues such as depression and anxiety are common in the chronic disease or cancer populations, I ensure capacity in a similar way with all patients - give patient info that is relevant to making informed decision, assess patient ability to understand the information, and also their ability to appreciate the situation and consequences. (Participant 15, NP, ROC, by email)

- I do not regard [mental illness] as an exclusion criteria for MAiD, but I carefully assess whether I feel like their thought process and content are clear and goal-directed, or if they are hopeless beyond the rational assessment of their circumstances. If I feel they are unable to rationally assess their circumstances, I would ask for a psychiatry opinion. This has not happened to me yet, as I find most patients requesting MAiD to have been quite rational in their thinking, despite some demoralization and their request for hastened death (Participant 12, MD, ROC, by email)

Note: $\mathrm{MAiD}=$ medical assistance in dying, $\mathrm{MD}=$ physician, $\mathrm{NP}=$ nurse practitioner, $\mathrm{ROC}=$ rest of Canada.

\section{Interpretation}

The 20 participants in this study were from across Canada, represented different medical specialties and collectively had a great deal of experience doing MAiD assessments. They felt confident with most assessments and relied on conversations 
with their patients about their choice for MAiD to get most of the information they needed. They were experienced clinicians who had assessed patients for other medical procedures, which may account for this finding. Our Quebec participants were more likely to use and document the Nova Scotia criteria than participants from the rest of Canada, but most participants talked about using the same elements of understanding, appreciating, reasoning and expressing a choice. ${ }^{9,10,22}$

When discussing challenging cases, the participants recognized that capacity fluctuates, and they were sensitive to the conditions of assessment such as time of day and environmental factors. Aids that facilitate communication (e.g., hearing aids or glasses) can also have an impact on capacity itself, since confusion and distraction arising from communication barriers can impede a patient's ability to understand and appreciate decisions. ${ }^{19,23-26}$

The importance of these findings is that specific tools may not be necessary to assess capacity to consent to MAiD and that experienced clinicians may be comfortable assessing in a wide range of cases. New assessors can learn from the strategies these clinicians used in challenging cases.

The 2019 report on MAiD in Canada reported that $7.8 \%$ of patients were found ineligible and $32.2 \%$ of those were ineligible because of lack of capacity. ${ }^{27}$ Most of the cases in which our participants found someone ineligible for MAiD because of lack of capacity were close to death and had varying levels of terminal delirium. These experiences were tied to their discussions about waiving the 10-day reflection period to prevent loss of capacity before the planned date.

Our participants rarely brought up the issue of concurrent mental illness as a challenge in assessing capacity unless they were prompted. This may have been because mental illness is not part of the eligibility criteria in the law ${ }^{1}$ and they concentrated instead on the specific aspects of capacity (determining whether the patient had the understanding, the appreciation and the reasoning ability, and was communicating choice). When prompted, they said that they assessed those with concurrent mental illness similarly to those without.

On Mar. 17, 2021, the Canadian law was changed to reflect the Truchon-Gladu court decision and created 2 streams - one for those with a reasonably foreseeable natural death and one for those without. ${ }^{28}$ It will be important to investigate how this change will affect capacity assessment for MAiD and how best to help trainees learn to do these assessments.

\section{Limitations}

Our study was limited to 20 assessors, but collectively, they had done thousands of assessments, were from 5 out of 10 provinces, were in different age groups, were from rural and urban areas, were from different specialties and included both nurse practitioners and physicians. They were mostly experienced MAiD assessors and so we had less representation of those who had only done a few assessments. Clinicians who focus their practices on providing MAiD tend to be active on the listserves, but we do not know how representative they are of all providers. Our participants were very experienced and, therefore, might be less likely to ask for psychiatric consults than less experienced assessors. Since 3 of the assessors were psychiatrists, they would not have referred to others for assessments. Further studies could evaluate this issue with more clinicians so that we could understand how their background and experience affected their approach. The French translations were not done by a professional translator nor were they back translated to verify the accuracy of the translation; however, the potential for error was mitigated as the investigator who conducted the interviews in French and did the translations (S.T.-H.) also participated in the analysis. Interview transcripts were not returned to the participants to be validated.

\section{Conclusion}

The participants in this study were comfortable doing MAiD assessments and used their clinical judgment and experience to assess capacity in ways similar to those used for capacity assessments in other clinical practices. The findings of this study suggest that experienced MAiD assessors do not routinely require formal capacity assessments or tools to assess capacity in patients requesting MAiD.

\section{References}

1. An Act to amend the Criminal Code and to make related amendments to other Acts (medical assistance in dying) (S.C. 2016, c. 3).

2. Chapter S-32.0001: Act respecting end-of-life care. Québec: Les Publications du Québec; updated 2020 June 1.

3. Starson v. Swayze, 2003 SCC 32, [2003] 1 SCR 722.

4. Aisen PS, Cummings J, Jack CR, et al. On the path to 2025: understanding the Alzheimer's disease continuum. Alzheimers Res Ther 2017;9:60.

5. Evans KG. Consent: a guide for Canadian physicians. 4th ed. Canadian Medical Protective Association; 2006, updated 2016. Available: www.cmpa-acpm.ca/ en/advice-publications/handbooks/consent-a-guide-for-canadian-physicians (accessed 2020 Apr. 2).

6. Appelbaum PS. Clinical practice. Assessment of patients' competence to consent to treatment. N Engl F Med 2007;357:1834-40.

7. Lim T, Marin DB. The assessment of decisional capacity. Neurol Clin 2011;29:115-26, viii

8. Ganzini L, Leong GB, Fenn DS, et al. Evaluation of competence to consent to assisted suicide: views of forensic psychiatrists. Am $\mathcal{F}$ Psychiatry 2000; 157:595-600.

9. Pennington C, Davey K, Ter Meulen R, et al. Tools for testing decisionmaking capacity in dementia. Age Ageing 2018;47:778-84.

10. Etchells E, Darzins P, Silberfeld M, et al. Assessment of patient capacity to consent to treatment. 7 Gen Intern Med 1999;14:27-34.

11. Tremblay M, Gobessi L, Spinks T, et al.; Mini Task Force on Capacity Issues, The Dementia Network of Ottawa. Determining capacity to consent: guiding physicians through capacity and consent to treatment law. Toronto: College of Physicians and Surgeons of Ontario; 2007. Available: www.cpso.on.ca/Physicians/ Policies-Guidance/Policies/Consent-to-Treatment.

12. Gather J, Vollmann J. Physician-assisted suicide of patients with dementia. A medical ethical analysis with a special focus on patient autonomy. Int 7 Law Psychiatry 2013;36:444-53.

13. Guidelines for conducting assessments of capacity. Toronto: Capacity Assessment Office, Ministry of the Attorney General; 2005. Available: www.attorneygeneral. jus.gov.on.ca/english/family/pgt//capacity/2005-06/guide-0505.pdf (accessed 2020 Apr. 2).

14. Appelbaum PS. Consent in impaired populations. Curr Neurol Neurosci Rep 2010;10:367-73

15. Gurrera RJ, Karel M, Azar AR, et al. Agreement between instruments for rating treatment decisional capacity. Am $\mathcal{F}$ Geriatr Psychiatry 2007;15:168-73.

16. Okonkwo O, Griffith HR, Belue K, et al. Medical decision-making capacity in patients with mild cognitive impairment. Neurology 2007;69:1528-35.

17. Moye J, Karel MJ, Gurrera RJ, et al. Neuropsychological predictors of decision-making capacity over 9 months in mild-to-moderate dementia. 7 Gen Intern Med 2006;21:78-83.

18. Owen GS, Richardson G, David AS. Mental capacity to make decisions on treatment in people admitted to psychiatric hospitals: cross sectional study. BM7 2008;337:a448.

19. Kagan A. Supported conversation for adults with aphasia: methods and resources for training conversation partners. Aphasiology 1998;12:816-30. doi: $10.1080 / 02687039808249575$. 
20. Lipscomb M. Abductive reasoning and qualitative research. Nurs Philos 2012;13:244-56

21. Kuckartz U. Qualitative text analysis: a guide to methods, practice \& using software. London (UK): SAGE Publications Ltd.; 2014.

22. Professional standard and guidelines regarding informed patient consent to treatment. Bedford (NS): College of Physicians and Surgeons of Nova Scotia; 2016. Available: https://cpsns.ns.ca/wp-content/uploads/2017/10/ Informed-Patient-Consent-to-Treatment.pdf (accessed 2020 Apr. 2).

23. Rubright J, Sankar P, Casarett DJ, et al. A memory and organizational aid improves AD research consent capacity: results of a randomized, controlled trial. Am 7 Geriatr Psychiatry 2010;18:1124-32

24. Fried-Oken M, Mooney A, Peters B. Supporting communication for patients with neurodegenerative disease. NeuroRebabilitation 2015;37:69-87.

25. Carling-Rowland A, Black S, McDonald L, et al. Increasing access to fair capacity evaluation for discharge decision-making for people with aphasia: a randomised controlled trial. Aphasiology 2014;28:750-65. doi: 10.1080/02687038.2014.895975.

26. Simmons-Mackie N, Raymer A, Cherney LR. Communication partner training in aphasia: an updated systematic review. Arch Phys Med Rebabil 2016; 97:2202-21.e8

27. First annual report on medical assistance in dying in Canada, 2019. Ottawa: Statistics Canada; 2020. Available: www.canada.ca/en/health-canada/services/ medical-assistance-dying-annual-report-2019.html (accessed 2020 Nov. 10).

28. Canada: Truchon v. Procureur général du Canada: Superior Court of Quebec finds limiting access to medical assistance in dying ("MAiD") to end of life unconstitutional. mondaq; 2019.

Affiliations: Department of Family Practice (Wiebe), University of British Columbia, Vancouver, BC; University of London (Kelly), London School of Hygiene and Tropical Medicine, Department of Epidemiology and Population Health, London, UK; Ontario Tech University (McMorrow),
Faculty of Social Science and Humanities, Legal Studies, Oshawa, Ont.; Université de Sherbrooke (Tremblay-Huet), Faculty of Law, Sherbrook, Que.; University of British Columbia (Hennawy), Kelowna, BC

Contributors: Ellen Wiebe and Thomas McMorrow conceived the project. Michaela Kelly, Sabrina Tremblay-Huet and Mirna Hennawy recruited, interviewed, transcribed and translated the interviews. All authors performed analysis and interpretation of the interviews. Ellen Wiebe drafted the manuscript and all authors revised it critically for important intellectual content. All authors gave final approval of the version to be published and agreed to be accountable for all aspects of the work.

Funding: The authors received funding from the Peter Wall Institute for Advanced Studies at the University of British Columbia.

Content licence: This is an Open Access article distributed in accordance with the terms of the Creative Commons Attribution (CC BYNCND 4.0) licence, which permits use, distribution and reproduction in any medium, provided that the original publication is properly cited, the use is noncommercial (i.e., research or educational use), and no modifications or adaptations are made. See: https://creativecommons. org/licenses/ by-nc-nd/4.0/

Data sharing: Data from this study are not available for use by other researchers.

Supplemental information: For reviewer comments and the original submission of this manuscript, please see www.cmajopen.ca/content/9/2/ E358/suppl/DC1. 